\title{
Segurança e defesa no Cone Sul: transições com transformações?'
}

SAMUEL ALVES SOARES*

\begin{abstract}
Resumo: As novas condicionantes da segurança internacional, em que não somente as soberanias e relações inter-estatais possuem peso significativo, têm ensejado mudanças nas possibilidades e exigências para as políticas de defesa. Países do Cone Sul procuram estabelecer novos parâmetros na definição de suas políticas, mas se encontram tensionados entre estabelecer políticas dissuasórias, como no passado, ou instituir mecanismos de cooperação com seus vizinhos. Por outro lado, estas políticas, pela sua natureza e amplitude, inserem-se sobre temas que não são exclusivamente militares. O objetivo do artigo é analisar as condicionantes estratégicas e definições estatais acerca da dissuasão e da cooperação em segurança internacional, e identificar o grau de autonomia e a natureza das concepções originadas das forças armadas na definição das políticas de defesa. Enfim, trata-se de verificar o grau de direção política do poder civil nas definições das políticas de defesa.
\end{abstract}

Abstract: The new conditions of international security don't only attach importance to sovereignty and interstate relations. This new framework has led to changes in the scope and requirements for Politics of Defense. Countries of the Southern Cone seek to establish new parameters in the definition of their policies, but need to define between dissuasive policies, as in the past, or establish mechanisms for cooperation with their neighbors. Furthermore, these policies, by their nature and size, are not exclusively militaries. The purpose of this article is to examine the definitions constraints on strategic deterrence and cooperation in international security, and identify the degree of autonomy and the nature of the concepts derived from the armed forces in shaping Politics of Defense. Finally, we try to check the level of civil policy direction in defining those policies.

Palavras-chave: Cone Sul. Políticas de defesa. Dissuasão e cooperação.

Key words: Southern Cone. Politics of Defense. Deterrence and cooperation.

* Professor na Universidade Estadual Paulista (UNESP/Franca), pesquisador do Grupo de Estudos de Defesa e Segurança Internacional (GEDES) e do Programa de Pós-Graduação em História da UNESP/Franca; Doutor em ciência política pela USP; Secretário-Executivo da Associação Brasileira de Estudos de Defesa. E-mail: samuel_soares@uol.com.br

1 Uma primeira versão deste trabalho foi apresentada no IX Congresso da Brazilian Studies Association - BRASA, New Orleans, março de 2008. Agradeço o inestimável apoio pelo levantamento de dados e notas redigidas pelo estudante Victor Hugo de Souza Gonçalves, bolsista PIBIC/CNPq, do curso de Relações Internacionais da Universidade Estadual Paulista - UNESP / Franca e membro do Grupo de Estudos de Defesa e Segurança Internacional - GEDES/UNESP.

Estudos Ibero-Americanos, PUCRS, v. XXXIV, n. 1, p. 160-180, junho 2008 
"Mientras más responsable o más abierto sea el régimen, más constructivo o más pacifista es su comportamiento internacional". "La falta de diálogo interno - a falta de pluralismo político [...] - redunda en desmedro de la política exterior".

JOSEPH TULCHIN

\section{Introdução}

Os processos de transição dos países do Cone Sul, e no caso particular de Argentina, Brasil e Chile, demarcaram singularidades, a refletir aspectos de seus regimes autoritários e de seus respectivos sistemas políticos. Contudo, havia convergências retroativas em determinados planos, entre os quais uma posição similar em relação à segurança nacional, entendida e orientada, prioritariamente, desde uma perspectiva interna, em que o inimigo encontrava-se no interior das fronteiras e se apresentava como extensão do movimento comunista internacional. Sem olvidar que, de maneira geral, os próprios militares se encarregavam de definir os inimigos, cingindo os períodos de exceção com uma marca indelével, e dos quais fazia parte, de maneira especial, o processo de crescente autonomia militar frente ao controle civil.

A internalização do conflito e a autonomia na definição do inimigo aparentavam estes países no contexto da Guerra Fria, e estabeleciam um duplo desafio para o futuro das transições. Não se tratava, decerto, de um processo em que os civis tão-somente retomassem o controle dos governos e das instituições políticas, o que certamente se apresentava como um desafio de larga complexidade. Havia ainda que se forjar outra perspectiva, na qual as forças armadas se voltassem para uma concepção clássica de defesa, situação em que o adversário, explícito ou não, encontra-se alhures. Externalizar o conflito foi parte das transições, ainda que estas questões não estivessem suficientemente claras à época. Em somatório, que a definição dos inimigos ficasse ao encargo do poder civil, o que somente se pode acolher em regimes efetivamente democráticos.

No que diz respeito à re-inserção do poder civil na condução política, as transições em cada um dos três países foram significativamente diversas. A diferenciação repousa, antes de mais nada, na natureza dos próprios regimes autoritários, como seu grau de discricionariedade e de excepcionalidade, nas resistências impostas aos atos de exceção e nas pressões para a sua abertura e término do autoritarismo, como também o grau de autonomia na condução do 
processo por parte de militares e civis ligados aos regimes autoritários. Na seqüência, as decisões políticas em relação à revisão do passado, com a responsabilização ou não dos atos cometidos e contrários aos direitos humanos e políticos.

Contemporaneamente, a questão ganha novos contornos, a exigir novos condicionamentos para a defesa, já que a segurança apresenta novos perfis, multifacetários, decorrentes das novas ameaças, que fragilizam fronteiras e tornam mais porosas e menos evidentes os riscos que advém de dentro e de fora dos países.

É neste campo, da segurança e da defesa, usualmente pouco analisado, que importa considerar o grau de direção política civil, destacando que aqui se conjugam elementos constitutivos das políticas externas e das políticas de defesa. As políticas externas compreendem diversos campos de atuação, e a elas se subordinam, por coerência, as políticas de defesa, que daquelas são parte constitutiva.

Outro ponto é que durante a Guerra Fria, salvo no plano das trocas de informações e da repressão política, os militares no poder alimentaram as rivalidades com países vizinhos. E estiveram imbuídos, com destaque para o caso brasileiro, de uma concepção orientada para a construção de um país potência no sistema internacional, ainda que dotados de concepções que estabeleceram como parâmetro a meta de se atingir o porte de uma potência média. Por esta razão, e por conseqüência de contenciosos do passado não suficientemente resolvidos, ou por considerações de equilíbrio de poder regional, a desconfiança mútua era a tônica das relações entre os países.

Embora as especificidades, um efeito conjunto das transições foi a efetivação de um novo padrão das relações sub-regionais ${ }^{2}$, com avanços em um leque de dimensões, entre elas o aprimoramento das relações de confiança, com a criação de mecanismos cooperativos.

Frente aos sistemas políticos internos, os militares vêm refluindo aos seus afazeres mais clássicos, sem descurar-se de que há prerrogativas prevalecentes, em um jogo em que se confrontam mecanismos de controle e espaços de autonomia preservada.

2 RUSSELL, Roberto. Cambio de régimen y política exterior: el caso de Argentina, 19761989. Buenos Aires: FLACSO, Documentos e Informes de Investigación No 88, 1989; HIRST, Monica y RUSSELL, Roberto. Democracia y política exterior: los casos de Argentina y Brasil. Buenos Aires: FLACSO. Documentos e Informes de Investigación $\mathrm{N}^{\circ} 55,1987$. 
Entretanto, as condições para a efetivação do controle civil sobre as Forças Armadas e de assunção dos civis à posição soberana de estabelecimento das diretrizes mais gerais das Políticas de Defesa não alcança resultados similares na Argentina, Brasil e Chile. Estas diferenciações podem ser explicadas, em certa medida, e este é um dos argumentos deste artigo, pelo tipo de transição à democracia verificada em cada país e pelo processo de condução política de temas que usualmente, até por inércia do poder civil, eram entendidos como sendo área restrita de decisão militar.

O objetivo é verificar em que medida se pode relacionar os tipos de transições aos processos de estabelecimento das Políticas de Defesa em três países relevantes da América do Sul. Fundamentalmente, trata-se de averiguar o grau de definição política civil na condução de um tema que pertence à cidadania, se entendida nos moldes democráticos e se as Forças Armadas tornaram-se ou estão se tornando atores não-deliberantes no âmbito mais específico da definição das políticas de Defesa.

\section{As transições na Argentina, no Brasil e no Chile}

São suficientemente conhecidos os modelos de transição propostos por Guillermo O'Donnell ${ }^{3}$. O autor os diferenciava pelo critério da forma, se pactuadas ou por colapso. No primeiro caso, a pactuação poderia ser fruto de um acordo explícito ou não. Ambos os modelos podem ser objeto de critica. Sendo o acordo explícito, não há muito que retificar. Entretanto, ao considerar implícita uma situação em que não há aceitação, mas simplesmente a constatação, por parte de distintos segmentos da sociedade civil, de que o grau de controle sobre o regime, por parte dos militares, é elevado e que não permite sequer a possibilidade de estabelecer acordos, torna menos plausível considerar a existência efetiva de um pacto. No segundo, não há, de fato, transição, mas sim o esfacelamento do regime autoritário. De todo modo, não é aqui a oportunidade de tratar do modelo em si, mas empregá-lo como ferramenta analítica, ainda que se lhe aponte algumas debilidades.

Pelo modelo proposto, na Argentina houve um colapso do regime. Um de seus resultados mais candentes, ainda que não se explique exclusivamente por esta variável, é que ao longo do tempo tornou-se perceptível a busca pela revisão de atos discricionários

3 O'DONNELL, Guillermo; SCHMITTER, Philippe e WHITEHEAD, Laurence. Transições do Regime Autoritário. Vértice: São Paulo, 1986. 
do passado, embora a existência de leis, nos primeiros momentos, que buscassem aplacar a busca pela justiça. Resultaram deste complexo processo um controle civil mais efetivo sobre as Forças Armadas e a redução da autonomia militar. Diversos segmentos da sociedade foram ocupando espaços importantes, em particular aqueles referentes ao campo das relações civis-militares. Destaquese o estabelecimento de diretrizes bastante claras para a Segurança e a Defesa.

Já no Brasil, a transição foi marcadamente controlada pelo regime anterior, que estabeleceu uma agenda para abertura, decerto com pressão civil originadas de diversas áreas, mas sem que as lideranças militares perdessem o controle sobre o cronograma e a extensão da abertura política e da transição, mesmo após o término do regime autoritário. Este formato, de participação hegemônica das Forças Armadas e baixo controle civil sobre estas mesmas forças, em que as demandas civis não foram suficientes para o predomínio do processo, conduziram a uma situação de avanços modestos e com medidas parcimoniosas. Por força destas características, atingiu-se uma transição pacificada, sem distúrbios significativos. A ausência de crises militares afastou o fantasma de um problema militar ao longo nos últimos vinte anos. O preço pago foi a ausência de uma revisão do passado, sem que a anistia estabelecida pelo próprio regime militar fosse retomada, embora a existência de pressões por parte da sociedade civil.

E no caso do Chile, nitidamente uma transição pactuada, com paulatina redução da autonomia militar e ampliação do controle civil. Aqui se configura um caso emblemático deste tipo de transição, pela aceitação, por parte da oposição, dos marcos da institucionalidade da constituição imposta por Pinochet, passo que inviabilizou rupturas e atitudes mais radicais. Também por parte deste processo, o pacto entre partidos de oposição que ajustaram uma estratégia de transição nos limites estabelecidos. A continuidade foi a elaboração do Livro de Defesa, que contou com a participação ampliada de distintos atores políticos.

O grau de autonomia é o segundo aspecto a ser evidenciado, e diz respeito às possibilidades de que as forças armadas estabeleçam, com relativa independência, as condições, a natureza e as prioridades de seu emprego, embora com grau distinto entre os parceiros do Cone Sul. Procura-se identificar se esta influência decorre de posicionamentos autônomos e propensos a estabelecer orientações próprias ou se atendem adequadamente ao estatuto da direção política do poder civil. 


\section{Da integração à cooperação em segurança}

Os conflitos entre os Estados-nação e em seu interior têm-se revelado, ao término do século XX, como um embate entre as batalhas clássicas e de alguma forma previsíveis e um formato de luta que se configura marcadamente pelo aspecto difuso, em que a forma de conduta dos contendores é menos visível, e bem mais complexa de ser antecipada. A emersão de novos atores, e a contrapartida do emprego da força pelos Estados-nação, insere-se no campo das novas ameaças, representadas pelo terrorismo, tráfico de seres humanos e de drogas, conflitos sociais, choques político-institucionais, entre outros. ${ }^{4}$ É neste contexto mais amplo que as questões de segurança e defesa ganham relevo com o processo de integração do Mercosul, que embora orientado para o âmbito econômico, fornece elementos adicionais para a cooperação também em outras esferas de atuação estatal, como as de defesa e segurança internacional.

Entretanto, ao se analisar o processo de integração econômica, pode-se cair na tentação de considerar que as estratégias de aproximação tenham sido similares, na medida em que refletiriam uma direção política claramente estabelecida e cumprida pelos agentes encarregados das negociações entre os países-membros do mercado comum. Esta busca pela integração econômica esteve conformada por um processo de novas injunções do capital financeiro mundial. Com a crise instalada no início da década de 80, uma nova agenda econômica foi sendo articulada e que visava, principalmente, readequar os parâmetros de acumulação, além de recolocar os EUA na posição de hegemonia mundial.

Os acontecimentos na ex-URSS aceleraram o processo, ou mesmo a débâcle soviética tenha sido reflexo das mudanças em curso. A nova compleição econômica pregava e exigia o fim da superprodução, do pleno emprego, de uma condução rígida dos déficits orçamentários das economias nacionais, de forma a garantir que os países capitalistas periféricos mantivessem condições de saldar suas dívidas externas, sem que houvesse sobressaltos aos investidores dos países centrais. Enfim, tratava-se de um processo de re-disciplinamento dos países periféricos. ${ }^{5}$

4 SAINT-PIERRE, Héctor. Reconceitualizando "novas ameaças": da subjetividade da percepção à segurança cooperativa. In: SOARES, Samuel A. e MATHIAS, Suzeley K. Novas Ameaças: dimensões e perspectivas. São Paulo: Sicurezza, 2003.

5 Ver, entre outros, TAVARES, Maria Conceição e FIORI, José Luis. Poder e dinheiro: uma economia política da globalização. Petrópolis: Vozes, 1998; OLIVEIRA, Marcelo Fernandes de. Mercosul: atores políticos e grupos de interesses brasileiros. São Paulo: Editora da UNESP, 2003. 
De outra forma, o re-disciplinamento dos países capitalistas periféricos implicou em choques externos sobre as economias nacionais, que impuseram sérias restrições ao desenvolvimento sustentado pela substituição das importações, fazendo com que os recursos indispensáveis para a redução das desigualdades sociais ficassem seriamente comprometidos.

A aproximação entre os países surgiu, em boa medida, mais pelas fraquezas e pelos colapsos (econômicos, militares etc.). Acentuou-se um esforço cooperativo de base comercial, emergindo, enfim, uma "nova ordem" de cooperação, não pela égide da dependência ou do terceiro mundismo, mas pelo pragmatismo imposto pela indução neoliberal, o qual se concretizou pela junção dos mais frágeis, como forma de ampliar o poder de barganha. É a severidade e uniformidade das crises econômicas que servem como base para as perspectivas comuns entre os países da região.

Neste contexto, a formação do Mercosul refletia este cenário de re-configuração da ordem mundial, e ao mesmo tempo orientava-se pela admissão de que o Cone Sul ${ }^{6}$ não se apresentava como região de marcado interesse internacional. Ao contrário, adotando-se uma perspectiva geopolítica, há um desinteresse estratégico pela região. Já em 1952, Golbery do Couto e Silva indicava o deslocamento da América do Sul, quer pelo afastamento dos principais eixos de circulação de riquezas, quer por distanciarse das principais linhas de tensão dos antagonismos internacionais. Trata-se de uma geopolítica ao revés, concebida não como projeção de poder, mas como "vazio que se busca preservar da ameaça de poder". $^{7}$

Na seqüência, e por força do quadro das novas ameaças, os interesses na área de segurança internacional e de defesa têm se apresentado mais convergentes entre os países. O intento norteamericano, durante o governo Clinton, de conceder novas atri-

6 Mercosul e Cone Sul não são empregados como similares. O primeiro refere-se ao ato formal decorrente de tratados e acordos. Já o Cone Sul indica uma região específica da América do Sul, a qual orbita em torno do eixo Argentina-Brasil-Chile. No que tange ao campo da segurança e defesa, é possível ora se referenciar ao Mercosul, do ponto de vista de sua natureza política, ora volta-se ao Cone Sul, como modo de entender a região, analiticamente, a partir de um sub-sistema regional. Outros analistas consideram a seguinte divisão para a América do Sul: Cone Sul (Argentina, Chile, Bolívia, Uruguai, Peru e Paraguai), Grã-Colômbia (Venezuela, Colômbia e Equador) e Brasil.

7 LAMAZIÈRE, Georges. Cooperação político-militar na América do Sul. Política Externa. v. 9, n.4, mar-abr-maio, 2001. 
buições às forças armadas da América Latina, constituindo-as como principal instrumento de combate ao narcotráfico, acabou por criar uma força amalgamadora adicional entre os militares da região, frontalmente contrários à proposta.

A Defesa, por seu caráter intrínseco de postura de contrareação ao emprego da força e a Segurança, que denota uma atitude de preparação para a tomada da iniciativa, começaram a fazer parte do rol de questões a serem debatidas para o esforço da cooperação. A cooperação para a defesa corresponde a duas ordens de questões. A primeira voltada para um campo de vigilância e controle de fronteiras, fortalecida pelo impacto das novas ameaças, somadas a ações de intercâmbio na área de inteligência, como monitoramento de possíveis atos ou movimentos terroristas. A segunda, como estratégia de ocupação de espaços no cenário internacional, enquanto ator integrado em bloco.

O pano de fundo desta análise reflete, portanto, dois aspectos centrais para o país e para o processo de integração regional. De um lado a busca de espaços de autonomia frente aos interesses dos EUA, e de outro, o quadro da construção da democracia nos países do Cone Sul, considerando as implicações do uso da força frente aos direitos e liberdades próprios de uma sociedade democrática.

De todo modo, a aproximação no campo da Defesa e Segurança pode conduzir à percepção de interesses comuns entre os países, ainda que o ponto de partida das relações bilaterais tenha historicamente se caracterizado por forte desconfiança, principalmente no campo da segurança. No presente, interesses e identidades são lentamente construídos, com base em estruturas institucionais, novas ou reinventadas, exigindo aprendizado e inéditas perspectivas entre os agentes estatais e mesmo não-estatais. São forças ideacionais ampliadas e renovadoras que impelem a novos patamares de entendimento. Sob a perspectiva do construtivismo, podem ter sido lançadas as bases para a consolidação de uma comunidade de segurança, cuja existência decorre da percepção mútua de que conflitos de interesses podem ser solucionados por outras vias, que não por meios bélicos. ${ }^{8}$

8 Para este ponto, ver HURRELL, Andrew. An emerging security community in South America? In: ADLER, Emanuel e BARNETT, Michael. Security Communities. New York: Cambridge, 1998. 


\section{As definições da agenda da cooperação e as concepções estratégicas}

Não se pode descurar que vigem no cenário internacional concepções arraigadas do paradigma realista das relações internacionais, e que influenciam a mentalidade militar no continente. Por este paradigma, recorde-se, estão presentes as concepções de equilíbrio de poder, aceitos explícita ou implicitamente. Nesta perspectiva, a guerra, as alianças e a diplomacia são os principais veículos através dos quais a distribuição de poder entre Estados é modificada. Os países do Cone Sul deliberaram, atuaram e atuam para que as alianças e a diplomacia sejam os instrumentos passíveis de serem empregados nas relações inter-estatais, ora aduzindo a um quadro mais realista, ora deixando antever posturas de ação orientadas por prismas um tanto diversos.

A aproximação no campo da segurança, principalmente entre Brasil e Argentina, foi fruto de uma iniciativa fundamentalmente política, nascida antes da ultrapassagem definitiva da era bipolar. Foi essa aproximação que permitiu, na questão da defesa e segurança regional, que esses países não apenas reduzissem antigas desconfianças e contenciosos, mas também que adotassem posições compatíveis quanto ao futuro de projetos militares - como na questão do armamento nuclear - e à ampliação do entendimento entre seus corpos militares, exemplificada pela realização conjunta ou combinada de exercícios e manobras castrenses.

A definição da percepção de amigos e inimigos pelo governo argentino durante e depois da ditadura foi bastante clara, uma vez que sob a égide militar havia o entendimento de que o país estava rodeado de inimigos - em especial Brasil e Chile - e que a melhor estratégia para o país nestas condições era a de uma concepção de segurança nacional, que primava, entre outros elementos, pela fortificação das forças armadas. Com a ascensão de um governo democrático houve uma ruptura drástica conduzida pelas autoridades civis para com esta compreensão, de modo paralelo a um amplo esforço diplomático no sentido de mostrar à comunidade internacional um novo perfil da Argentina guiado por uma racionalidade em sintonia com os "valores" ocidentais. ${ }^{9}$

9 DIAMINT, Rut Clara. Cambios en la política de seguridad. Argentina en busca de un perfil no conflictivo. In: FASOC, vol. 7, n. 1. 
A estratégia da dissuasão vigente à época da ditadura seguia a lógica de que com o fortalecimento do poderio ofensivo, assim como do defensivo, através de uma melhora qualitativa da tecnologia disponível para as forças armadas, a possibilidade de que um inimigo externo viesse a desafiar quaisquer estratégias do país reduzir-se-iam consideravelmente, de modo que a Argentina deveria estar preparada para o combate.

Para o aumento das capacidades militares do país, era entendido como indispensável a realização de investimentos extensivos em ciência e tecnologia, que, por sua vez, permitiriam o desenvolvimento de armamentos de alto nível tecnológico. Dentre os frutos deste empenho, o programa Condor II desponta como o mais notável projeto desenvolvido, estendendo-se, inclusive, até o início do governo democrático. ${ }^{10}$

No que tange à área nuclear, o desenvolvimento tecnológico argentino aparece, nos anos 1970 e 1980, como o mais avançado dentre os países latino-americanos. Durante o período autoritário, o governo recusava-se a aderir ao Tratado de Não-Proliferação de Armas Nucleares (TNP) e ao Tratado de Tlatelolco. ${ }^{11}$ Os trabalhos da Comissão Nacional de Energia Atômica, submetida à época ao comando militar, gerou acentuadas desconfianças na comunidade internacional, em especial nos países vizinhos e nos Estados Unidos, que visualizavam uma possível tentativa dos argentinos de desenvolver armamentos nucleares. Levando-se em conta a racionalidade militar do período, tais receios não eram totalmente infundados.

No Brasil, por sua vez, lógica similar à adotada na Argentina estava em pleno vigor, e o desenvolvimento de tecnologia nuclear era considerado um direito inalienável de desenvolvimento do país. Essa linha de pensamento levou os diplomatas brasileiros a postergar a adesão efetiva ao Tratado de Tlatelolco, visto que o mesmo impunha entraves à realização de explosões nucleares pacíficas - possibilidade contemplada pelas autoridades.

10 SMITH, William C. e ACUÑA, Carlos H. A política da "economia militar" no Cone Sul: Análise Comparativa da Democracia e da Produção de Armas na Argentina, no Brasil e no Chile. Contexto Internacional, Rio de Janeiro, vol. 16, n.1, janeiro/junho 1994, p. 7-51.

11 O Tratado de Tlatelolco tinha como objetivo estabelecer uma zona livre de armas nucleares na América Latina, e foi fruto de uma proposta, originalmente, do governo brasileiro, anterior ao golpe militar de 1964, que encontrou eco em alguns países, com destaque para o México, que se tornou seu principal defensor e responsável pela materialização da proposta. 
Neste contexto, o TNP foi, também, rechaçado pelo Brasil, sendo entendido como um instrumento discriminatório que criava duas classes de países: os que tinham o direito de possuir artefatos bélicos atômicos e aqueles que não dispunham de tal direito. A mesma postura foi adotada - mais uma vez - pela Argentina e pelo Chile. O pensamento estratégico predominante, entre os militares dos três países, considerava que finalidade real do TNP era o congelamento do poder mundial em benefício das grandes potências.

Apesar de as autoridades da Argentina e do Brasil não terem explicitamente alegado o objetivo de desenvolver armas atômicas através de seus programas nucleares, havia uma desconfiança recíproca entre os dois países de que o outro pudesse estar tentando de algum modo adquirir esse tipo de arsenal bélico, o que estimulava ainda mais uma lógica armamentista. Tais percepções foram amplamente alimentadas pela existência de uma rivalidade histórica entre seus países, somada ao fato dos dois governos serem conduzidos pelos militares e, por extensão, por suas visões de mundo.

Após a fragorosa derrota das forças armadas argentinas na Guerra das Malvinas e da situação econômica do país, os militares argentinos não encontraram outra saída que não o abandono do poder em prol da emergência de um governo liderado por civis. Tal mudança de regime abrupta não possibilitou aos militares influenciar os rumos relativos à estratégia e política externa da nação, sendo os mesmos submetidos imediatamente ao comando civil.

A fim de fugir da lógica imperante ao longo da ditadura, o governo civil do presidente Raúl Ricardo Alfonsín iniciou diálogo direto com o Brasil, em matéria de ciência e tecnologia nuclear (área bastante sensível para ambos). Ensaiava, desse modo, uma aproximação política significativa que culminou - ainda durante a transição para o regime democrático no Brasil - na Declaração Conjunta sobre Política Nuclear de Foz do Iguaçu, assinada no ano de 1985 por José Sarney e Alfonsín.

Após o governo Alfonsín, houve uma "mudança radical nos quadros conceituais utilizados pelos policy makers e nas idéias que embasavam a política externa"12 , de maneira que a idéia de que as

12 ARBILLA, José María. Arranjos institucionais e mudança conceitual nas Políticas Externas argentina e brasileira (1989-1994). Contexto Internacional, Rio de Janeiro, vol. 22 n. 2, julho/dezembro 2000, p. 338. 
relações com os países desenvolvidos (em especial, os Estados Unidos) deveriam ser o centro das preocupações do país. Sob o ponto de vista de uma análise particular, o governo Menem impôs ao seu país uma ampla auto-subordinação aos interesses norteamericanos, em uma tentativa de obter uma resposta de Washington no que se refere a investimentos de capitais e transferência tecnológica, a fim de que a Argentina pudesse inserir-se exitosamente na nova ordem internacional do pós Guerra Fria.

Sob pressão do governo Reagan - veementemente contra a possibilidade de que países do então "Terceiro Mundo" viessem a desenvolver armamentos de alta tecnologia e que os mesmos pudessem chegar a outros países, como Egito e Iraque - Menem encerrou o projeto Condor II. Com isso, o presidente argentino teve de enfrentar vasta oposição interna, advinda dos militares (em especial da Força Aérea) e da iniciativa privada envolvida neste projeto específico, visto que os mesmos haviam dedicado tempo, dinheiro e diligência em porções significativas para concretizar a produção de um míssil de médio alcance. Desta forma, não aceitaram facilmente que seus esforços fossem descartados pelo que era considerado como um capricho de um político.

Com a finalidade de demonstrar aos países do Norte o comprometimento do governo argentino pós-ditadura para com a "lógica da segurança ocidental", ou seja, favorável aos regimes de não-proliferação e de transparência em matéria de tecnologias sensíveis, as autoridades empreenderam considerável esforço para dar continuidade à cooperação com o Brasil. $\mathrm{O}$ aprofundamento desta aproximação ocorreu via visitas presidenciais mútuas às instalações nucleares de cada país, assim como por intermédio de outras declarações conjuntas, que, entre outros resultados, permitiram a criação do Sistema Comum de Contabilidade e Controle de Materiais Nucleares (SCCC), controlado pela Agência Brasileiro-Argentina de Controle e Contabilidade de Materiais Nucleares (ABACC). As elites administrativas da Argentina prosseguiram em seu esforço de redução das desconfianças internacionais, submetendo-se, ao lado do Brasil, às salvaguardas da Agência Internacional de Energia Atômica (AIEA), por meio do Acordo Quadripartite.

Em continuidade às ações até então tomadas, o governo de Menem decidiu que o Tratado de Tlatelolco deveria entrar em vigência para o seu país. Optou ainda pela ratificação do TNP, visto que não fazia mais sentido para os argentinos permanecer fora de 
quaisquer regimes internacionais que visassem proibir a aquisição de armas nucleares, dado que os mesmos já haviam sinalizado, anteriormente, o caráter pacífico de sua tecnologia atômica.

É possível interpretar tais ações como inseridas em um empenho maior dos governos brasileiro e argentino para criação de um ambiente de segurança cooperativa, em que o tradicional equilíbrio de poder seja substituído pela lógica da confiança recíproca.

No caso do Brasil, o processo de adesão a diferentes regimes de não-proliferação, na primeira metade da década de 1990, deu-se concomitantemente a um complexo processo evolutivo do quadro conceitual da Política Externa, e institucional do Ministério das Relações Exteriores. Neste sentido, diferentes atores, em nível individual $^{13}$, exerceram influência no referido período, seja para conferir um caráter político à Política Externa ou para manter a tradição do domínio institucional dos diplomatas de carreira. ${ }^{14}$

O Brasil, diferentemente da Argentina, levou certo tempo para aceitar a lógica de que o TNP era um mecanismo que atendia a seus interesses. Para determinadas lideranças políticas e militares, a cooperação com a Argentina, assim como a submissão às salvaguardas da Agência Internacional de Energia Atômica, via o Acordo Quadripartite, e a adesão ao Tratado de Tlatelolco eram consideradas garantias mais do que suficientes da natureza pacífica do programa nuclear do país. ${ }^{15}$

Em meio a esta percepção, outra ala de atores políticos capazes de exercer grande influência sobre as decisões finais concernentes à Política Externa (como o ex-presidente da República Fernando Henrique Cardoso e o ex-chanceler Luiz Felipe Palmeira Lampreia), passou a amadurecer a idéia de que a ratificação do TNP era indispensável ao desenvolvimento do país e à inserção do mesmo em um patamar mais elevado no cenário internacional. Este grupo passou a defender a concepção de que outras nações relevantes passariam a conferir maior credibilidade ao Brasil com um ato deliberativo de adesão, resultando, assim, em uma maior transferência de tecnologia e aumento de investimentos. Desse modo, o debate

13 Entre eles, os ex-presidentes Fernando Affonso Collor de Mello e Itamar Augusto Cautiero Franco, assim como os ex-chanceleres Francisco Resek, Celso Lafer, Fernando Henrique Cardoso e Celso Luís Nunes Amorim.

14 Ibidem, p. 350-362.

15 WROBEL, Paulo S. O Brasil e o TNP: Resistência à Mudança? Contexto Internacional, Rio de Janeiro, vol. 18, n. 1, janeiro/junho 1996, p.143-156. 
nacional acerca da adesão ou não ao tratado evoluiu, culminando em julho de 1998 na ratificação do mesmo.

Paralelamente a isso, o Brasil viveu um período de transição sem sobressaltos desde Itamar Franco, que foi sucedido por Fernando Henrique Cardoso exercendo dois mandatos, e depois por Luiz Inácio Lula da Silva. Ainda que alguns analistas apontem diferenças nas Políticas Exterior e de Defesa, a prioridade dada por todos esses governos à consolidação da democracia e à estabilização econômica fez com que fosse mantido um clima de estabilidade na condução desses assuntos. Estabilidade, aliás, tem sido o maior interesse do Brasil no tocante à política (consolidação da democracia em todo o subcontinente), à economia e à segurança regional, pois quanto menores os conflitos e sobressaltos, maior a desenvoltura do país (e dos países da região) na consolidação de uma imagem de região amadurecida para receber investimentos internacionais. Daí a convergência do Brasil aos tratados internacionais de segurança e controle de armas, e também a adesão do Brasil aos programas de liberalização econômica.

Este quadro favorável em relação a temas de significativa sensibilidade não autoriza considerar, entretanto, a sustentação convergente de posturas frente à dimensão militar-estratégica, já que, para o Brasil, o conceito de Segurança Cooperativa era visto como "manifestação dos EUA para exercer uma política hegemônica na região". ${ }^{16}$

Externamente, por outro lado, a partir do fim da Guerra Fria, que desenhava uma geometria de forças bipolar, os organismos internacionais, particularmente as comissões orientadas para os temas da Segurança Internacional, iniciaram a discussão sobre os conceitos tradicionais de Segurança procurando a nova fisionomia das ameaças. No Hemisfério, este processo pode ser percebido pela preocupação, no seio da Organização de Estados Americanos (OEA). Ainda assim, mesmo interpostos novos conceitos, que subtraem do campo militar a componente quase exclusiva do debate teórico e normativo sobre a Segurança Internacional, é possível observar que as forças armadas, com destaque para as do Brasil, ainda se orientam por uma perspectiva clássica de defesa

16 CORTES, Maria Julieta. Argentina e Brasil nos anos 1990: convergências e divergências em uma relação estratégica. In: MATHIAS, Suzeley Kalil e VILLA, Rafael Duarte. Ensaios latino-americanos de política internacional. São Paulo: Hucitec, 2007. 
territorial e de garantia da soberania estatal, com forte traço realista, ainda que não cause bloqueios intransponíveis ao entendimento.

Para comparar as orientações políticas e estratégicas da delicada equação da dissuasão e da cooperação, servem de base para a análise cinco documentos normativos que versam sobre as questões de defesa de Argentina, Brasil e Chile. O documento Política de Defesa Nacional, de 1996, durante o primeiro governo de Fernando Henrique Cardoso, o Decreto-Lei 5484, que instituiu a Política de Defesa Nacional do governo Luis Inácio Lula da Silva, o Libro Blanco de la República Argentina e a Ley de Defensa Nacional, da Argentina, de 1988. Ainda como parâmetro de análise haverá referências às diretrizes do Comandante do Exército, para o caso brasileiro, e do documento Estudio comparado de políticas de Defensa, da Argentina, e o acalantado e minucioso Livro de Defesa Nacional do Chile. Visa contemplar os fatores e condicionantes das Políticas de Defesa e tratam de sua Orientação Geral; dos Pressupostos para a Defesa, da Integração e Cooperação Regional, da Orientação Estratégica e da definição de elementos da Dissuasão e da Cooperação.

Antecipadamente é necessário referir-se às diferenças de forma e encaminhamento das definições das políticas de defesa de Argentina, Brasil e Chile. A Argentina configurou, no Libro Blanco, um alentado estudo analítico acerca dos parâmetros mais gerais de sua política de defesa, procedimento que contou com a participação de vários setores do Estado e de outras instituições. $\mathrm{O}$ documento trata de cenário estratégico, da dimensão continental, do contexto geográfico do país, dos marcos legais para a defesa, dos interesses nacionais, das políticas de defesa, definindo os campos de ação, da modernização e reestruturação das forças armadas, da redefinição das missões destas forças, de suas funções comuns e específicas e da condução geral da defesa, inclusive com as diretrizes para o orçamento de defesa. Este detalhamento é producente e bastante claro nas atribuições de papéis e funções.

O Brasil carece de um esforço desta natureza, que redundasse em um direcionamento mais detalhado da sua orientação políticoestratégica para a segurança e a defesa. Por força desta característica, os documentos estabelecidos como políticas de defesa obrigam-se a incorporar definições e conceitos, o que é ainda mais perceptível na Política de Defesa instituída no governo do presidente Lula. Ausente este procedimento de consulta e deliberação, peça importante para um maior adensamento de critérios demo- 
cráticos, até pela possibilidade de um possível maior consentimento e legitimidade acerca das propostas, as políticas de defesa apresentam orientações de um grupo mais restrito de atores.

No caso chileno, a participação ativa de vários setores da sociedade civil e política conduziu à produção de um Livro de Defesa detalhado e coerente com suas premissas básicas. O documento delineia o quadro internacional e os ditames dos conflitos existentes no sistema internacional, o desafio estratégico que considera as peculiaridades geográficas do país, a política de defesa, os meios e a preparação para a defesa, a sua organização e os recursos necessários para a sua efetivação. Acrescenta os cenários e os entornos para a defesa, assim como os procedimentos para a mobilização nacional e para o serviço militar.

Pelo critério da participação ampliada de atores na formulação das políticas de defesa, mais uma vez se configura um quadro tributário do tipo de transição política e do empenho em produzir uma direção política civil às forças armadas.

Quanto à cooperação em segurança e defesa, os documentos analisados refletem um caráter mais retórico, pela ausência de uma definição unívoca sobre as bases das políticas de defesa e as possibilidades de cooperação. As referências à cooperação regional não são substantivas nas políticas de defesa dos três países. Assinala-se a integração regional na PDN do governo Lula, como forma de atingir a autonomia estratégica via indústria de defesa. O enfoque sobre a cooperação é de caráter mais geral, sem que seja contemplada a sua efetivação.

Entretanto, a Estratégia de Dissuasão versus Projeção de Poder está claramente especificada nas Diretrizes do Comandante do Exército $^{17}$, para o caso brasileiro, que, todavia, é documento anterior ao atual Decreto-Lei. Após quase dois anos de sua decretação, a referida diretriz manteve a sua redação original, sendo substituída apenas em 2007.

A Diretriz incorre em três questões que merecem análise. Primeiramente, planeja o emprego da Força a partir de um cenário em que o país alcança um novo patamar de inserção econômica no cenário internacional. Um melhor posicionamento na esfera econômica atrairia para o país distintos interesses, tornando-o alvo de cobiça. O ponto essencial é que altera significativamente a atuação

17 Diretriz Geral do Comandante do Exército - 2003. Disponível em www.exercito.gov.br. Acessado em 14 de julho de 2005. 
estratégica do país para a defesa. A afirmativa da transição de uma estratégia de caráter dissuasivo, para outra de projeção de poder, implica em modificações na formação militar, ao menos no âmbito da estratégia, reestruturação e re-equipamento do Exército, como também modificações na sua distribuição territorial.

Neste aspecto, o documento analisado é bastante explícito, enquanto identifica um cenário em que a atuação do Exército é cada vez mais voltada para o âmbito externo, em um processo paulatino de distanciamento de questões internas ao país. Pode-se notar o que seria uma reviravolta na mentalidade militar brasileira, fortemente influenciada na perspectiva de dotar recursos de força para sanar o que foi identificado, em outras oportunidades, como crises institucionais, cujo desfecho somente poderia ser resolvido pela aplicação da força militar. Note-se, contudo, que o Exército Brasileiro reestruturou a sua organização, e estabeleceu, em nível de grandes unidades, tropas encarregadas da Garantia da Lei e da Ordem.

Do ponto de vista das relações exteriores, e mais especificamente no campo da cooperação em defesa, este posicionamento do Exército poderia implicar em que os países vizinhos o interpretassem como atitude unilateral e contrária à ampliação da cooperação. Neste campo, tão sensível, os cuidados devem ser redobrados e a transparência é a peça central para a criação e o aprofundamento de uma relação de confiança mútua. Os parceiros, ao contrário, podem entender que se trata de ampliação do poder militar, sem a devida contrapartida.

Por fim, um terceiro ponto é identificar em que proporção este posicionamento do Exército Brasileiro impõe-se como uma direção política advinda da autoridade legitimada pelas urnas. Desconhecem-se documentos governamentais que respaldem este posicionamento, em um indicativo de que, mais uma vez, pelo desmazelo do poder civil, que não atenta para as questões estratégicas do país, as próprias Forças Armadas chamem para si a responsabilidade de definir aspectos chaves e centrais para o Estado. Não se trata aqui de indicar incompetências quanto à capacidade de formulação de políticas públicas, já que é de se esperar que as forças castrenses, profissionais da violência estatal, sejam impelidas a apresentarem propostas neste sentido. A questão central é que a decisão final cabe ao poder civil. A conjugação da ausência do exercício do mando pelo poder político, aliada aos espaços de autonomia do aparelho militar, acabam por criar estas 
situações, com implicações embaraçosas, ou até complicadoras, para a política externa do país.

Do lado argentino, o documento Estudio Comparado de Políticas de Defensa $a^{18}$, indica, com ênfase, a permanência, na Política Externa Brasileira, do objetivo de o Brasil converter-se em potência mundial de primeira ordem, ressaltando o "destino manifesto" do Estado brasileiro, na conhecida expressão de Golbery do Couto e Silva. Favorece esta interpretação a emissão, no Brasil, da citada Diretriz Geral do Comandante do Exército para o ano de 2003. O documento define, para o longo prazo, novos critérios de preparação para a Força, assentados sobre uma nova variável estratégica. Ao considerar, acertadamente sob o ponto de vista da Política Externa, a preponderância absoluta da Estratégia da Dissuasão, adverte sobre a necessidade de incremento da Projeção de Poder. Na seqüência, o documento defende explicitamente a transição progressiva de uma Estratégia de Dissuasão para outra de Projeção de Poder.

\section{Da dissuasão à cooperação?}

Por fim, cabe uma diferenciação conceitual entre integração e cooperação ${ }^{19}$. A estratégia de integração, por sua própria natureza e amplitude, impõe um maior grau de exigência. Interpõe a transferência progressiva de certas competências relevantes da soberania dos Estados a instâncias administrativas ou eletivas transnacionais. O princípio condutor é o da supranacionalidade e as tomadas de decisão decorrem de votação majoritária. É o caso da União Européia, em que instituições cumprem este papel supraestatal. O Mercosul não atinge este grau de integração, a par os regimes estabelecidos em outras áreas.

Por sua vez, a estratégia da cooperação é bem menos ambiciosa. ${ }^{20}$ Tende a harmonizar e coordenar políticas originadas dos próprios Estados, sem que a soberania de cada um seja afetada. A unanimidade é o princípio orientador, a partir de ações conjuntas

18 Estudio Comparado de Políticas de Defensa, editado pelo ministério da Defesa e Estado Mayor Conjunto de Las Fuerzas Armadas, Centro de Estudios Estratégicos, Argentina, 2003.

19 QUERMONNE, Jean-Louis. Le système politique de l'Union européenne. 3. ed. Paris: Editions Montchrestien, 1998.

20 Tema tratado em SOARES, Samuel A. e OLIVEIRA, Leonardo S. Meios nucleares para a defesa: vetor de dissuasão ou de cooperação no Cone Sul? Um estudo do caso brasileiro. Strategic Evaluation, International Journal of Defence E Conflict Analysis, n. $1,2007$. 
estabelecidas por instâncias intergovernamentais. No Mercosul, as questões de defesa são orientadas por esta estratégia, com papel relevante para as próprias forças armadas dos países, que têm estabelecido uma série de ações conjuntas, principalmente a partir da década de 1990.

A cooperação, entretanto, está limitada a atuações em exercícios conjugados, reparos de equipamento militar e intercâmbios educacionais. Configura-se superficialmente a possibilidade de efetivação de uma Cooperação em Defesa e Segurança Regional, que implicasse em unidades militares binacionais ou regionais, compatibilização e aquisições conjuntas de equipamento militar e definição de estratégias comuns de defesa, e cujo desfecho conduzisse à efetiva seleção de objetivos estratégicos convergentes.

As possibilidades que se abrem à decisão política de mais alto nível estão inseridas em um cenário no qual é possível constatar uma capilarização da violência, em um cenário pós-westphaliano, e cujas características decorrem da perda, pelos Estados e mais ou menos intensa, do monopólio da aplicação legítima da violência. ${ }^{21}$ A perda do monopólio se daria muito mais pela falência dos Estados, e não pela afirmação do poder da violência. A implicação geral e essencial desta situação é de que a violência e a segurança não poderiam ser analisadas tão-somente pela ótica militar ou interestatal, mas com base em múltiplas formas de insegurança.

A multipolarização dos riscos e a difusão da violência, isto é, sua desterritorialização, são evidências que trazem novos riscos, como a exacerbação da ação dos Estados, em busca de reconquistar sua posição monopólica da aplicação da violência, como também o risco dos países de direito, na concepção de Buzan, que se encarregam de substituir os Estados falidos ou quando tentam compelir a que a força ganhe novas dimensões, mesmo com os desastrosos danos aos direitos humanos.

A violência contemporânea dirige-se para outros fins, que não a anexação de territórios ou contenciosos de fronteira, que geravam as formas clássicas de guerra. Amplia-se e se descortina pelas novas ameaças já citadas, mas também com o aprofundamento das assimetrias econômicas, via financeirização do capital, com a biopirataria geradora de lucros abusivos para os grandes monopólios farmacêuticos, se efetivamente ao se pensar em ameaças não só os

21 BUZAN, Barry. People, State and Fear. The National Security Problem in International Relations. Brighton: Harverster, 1983. 
Estados e a ordem internacional, mas também as sociedades e os indivíduos forem considerados. Por esta razão, a segurança não pode mais ser abordada de um ponto de vista estritamente militar e político, mas deve integrar considerações de ordem econômica, social e cultural.

A primeira característica da violência é que é polimórfica e se transforma permanentemente para se adaptar aos seus objetivos. O sistema internacional, nestas condições, vive à sombra da guerra, há uma lógica permanente do conflito, sendo a paz uma mera trégua, na já tão conhecida expressão do realismo clássico. O que vigora é o enfrentamento permanente do poder dos Estados contra os demais, podendo manifestar-se em uma luta espacial, mas também com facetas econômicas, políticas e ideológicas.

Se assim é, cada Estado vê-se compelido a elaborar um projeto nacional para o incremento do poder nacional, de modo a sair vitorioso em suas operações de aplicação da força, interna ou externamente. A falência de parte considerável dos Estados nesta tarefa cria um paradoxo alarmante, na combinação de força com a falência de outras possibilidades de redução da violência.

Este quadro impõe novos elementos para a emergência de uma cooperação em defesa entre os países do Cone Sul e implica, sempre mais, na participação efetiva de outras instâncias e instituições sociais na análise e definição das políticas de defesa nacionais.

Em síntese, a cooperação para a defesa corresponde a duas ordens de questões. A primeira voltada para um campo da vigilância e controle de fronteiras, fortalecida pelo impacto das novas ameaças, somadas a ações de intercâmbio na área de inteligência como monitoramento de possíveis atos ou movimentos terroristas. A segunda, como estratégia de ocupação de espaços no cenário internacional, enquanto ator integrado em bloco.

O pano de fundo desta análise reflete, portanto, dois aspectos centrais para o processo de integração regional. De um lado, a manutenção de espaços de autonomia frente aos interesses dos EUA, e de outro, o quadro da construção da democracia nos países do Cone Sul, considerando as implicações do uso da força frente aos direitos e as liberdades próprios de uma sociedade democrática. Neste caso, se inserem as prerrogativas militares, como no caso brasileiro, em que a ausência de um Livro de Defesa favorece que as Forças Armadas estabeleçam suas Estratégias Militares de Defesa, ainda que não convirjam com a Política de Defesa. 
É possível considerar que a elaboração dos Livros de Defesa, e a forma como foram produzidos, com maior participação de diversos atores, contribuem para conceder-lhes uma perspectiva de Defesa que reflete interesses de Estado e da sociedade e não apenas de governos, e reduzem as possibilidades de atuação autônoma das instituições militares.

O debate e a elaboração dos Livros de Defesa de Argentina e Chile conferem um patamar mais democrático às suas políticas de defesa. No Livro de Defesa do Chile afirma-se que

La Política de Defensa es una política de Estado en tanto exige estar por sobre la coyuntura política y trascender los proyectos y la acción de los sucesivos gobiernos del país. Como política estatal es una política pública y, por tanto, debe estar sujeta a las condiciones generales de formulación, implementación y verificación de las demás políticas públicas, incluida la del sometimiento a la observación y opinión de los ciudadanos.

Além disso, é preciso destacar que os acordos e anúncios indicativos de redução das desconfianças na área de defesa e segurança são, de fato, sedimentações de posições nas quais não existem mais contenciosos significativos. O ponto de partida, de desconfianças mútuas, não reflete discrepâncias e menos ainda antagonismos acentuados. Porém, a ausência de hostilidades reduz o impacto das medidas adotadas, já que não significam uma operação meticulosa de construção de consensos. Contrariamente, a plataforma de aproximação configura-se como uma busca de institucionalização de uma realidade já existente. Este é um limite para as possibilidades de aprofundamento para uma cooperação em defesa, pois não há demandas significativas a serem solucionadas e o bloco parece evidenciar que não se compreende como um ator coletivo, em busca de defender interesses comuns na área de defesa e segurança.

Permanecem, na região, desafios clássicos aos seus sistemas políticos. Orientar as definições estratégicas de Defesa e de Segurança Internacional em atendimento não apenas aos intitulados interesses nacionais, mas que respondam aos reclamos das sociedades e dos indivíduos. Estes esforços colidem com mentalidades ainda predominantes que denotam concepções para as quais no campo internacional, e sub-regional, a cooperação é momentânea e pontual, a ser ultrapassada por inevitáveis conflitos e pelo uso da força. As apostas na paz e na condução política civil das políticas de defesa constituem o apelo para que as transições políticas conduzam a transformações significativas. 